\title{
Report from the Embargo Workgroup
}

\author{
Glenorchy Campbell, Gregg Gordon, Laura Helmuth, Danny Kingsley, Eric Massant, Audrey McCulloch, \\ Gail McMillan, Tony Peatfield, Ann Riley, Will Schweitzer, Keith Webster
}

\begin{abstract}
The Embargo workgroup began by defining "embargo," encapsulating it into four main types and then focusing on the post-publication and subscription embargoes. Among other things, we discussed the dispersed nature of usage metrics and their possible impact on the duration of embargoes. This, in part, led us to recognize the lack of an evidence on which to base decisions surrounding the need for embargoes and their duration. Therefore, we focused on what it would take to address the key issue: 'What are the impacts of embargoes on scholarly communication?' We concluded by considering how to fund a global survey of key stakeholders and what data the survey should collect in order to provide data about the issues surrounding embargoes.
\end{abstract}

\section{OSI2016 Workgroup Question}

In an information system where so much information is destined for subscription journals, the assumption has been that embargos allow publishers time to recoup their investments, and also allow the press time to prepare news articles about research. Is this assumption warranted? Why or why not? Is the public interest being served by embargos? What about by embargos on federally-funded research? Are there any facts or options that haven't yet been considered to address the concerns animating the embargo solution?

The Open Scholarship Initiative (OSI) has laid the groundwork for creating a global collaborative framework to guide the future of scholarly communication and everything these practices impact. OSI2016 workgroups addressed many complex issues including embargoes. The first question the Embargo workgroup addressed was what does 'embargo' mean? ${ }^{1}$ We agreed that embargo means a period of time during which there is restricted access to published content. We identified four types of embargo:
Pre-publication embargoes: Some journalists enjoy pre-publication access (usually for 3-4 days) to scholarly articles so that they can distil the article for public consumption. Other purposes may be to create readerfriendly graphics, or to prepare the scholars for interviews. This type of embargo may be seen to benefit journalists and the public, though some scientists are not happy with any delay, even a few days, in making their findings available. Another problem may arise following the press release when consumers are locked out of the

C 2016 OSI2016 Embargo workgroup. This open access article is distributed under the Creative

Commons Attribution 4.0 International License. This document reflects the combined input of the authors listed here (in alphabetical order by last name) as well as contributions from other OSI2016 delegates. The findings and recommendations expressed herein do not necessarily reflect the opinions of the individual authors listed here, nor their agencies, trustees, officers, or staff. 
scholarly article because it has a postpublication embargo.

\section{Post-publication and subscription} embargoes: Post-publication embargoes refer to access restrictions to the Accepted Manuscript (AM), deposited in institutional or subject repositories. Subscription embargoes refer to access restrictions to the Version of Record (VoR), unless a subscription to the journal in which it is published is purchased. Many funders have policies that require freely available access to the AM after the post-publication embargo has expired, or immediate access to the VoR, should an Article Publication Charge be paid. Open access to clinically relevant articles from the American Cancer Society, the American Diabetes Association, the American Heart Association, and other organizations has at times been negotiated in order to permit patient access. Similarly, the Zika virus outbreak led to various foundations (Gates, Wellcome, etc.) agreeing to immediately release any information that might have value in combatting the virus and assuring that doing so would not preclude researchers from subsequently publishing papers. ${ }^{2}$

No-publication embargoes: These may be government or university imposed, for example to protect information that is not meant to be publicly available. Embargoes might be in place, for example, during a patent application, or to protect a product from being commercialized prematurely.
Our discussions focused largely on postpublication and subscription embargoes, as well as the Academy, where much information is destined for subscription journals. In these publication models, the assumption has been that embargoes allow publishers time to recoup their investments through subscriptions and to meet the expectations of their shareholders. Another assumption is that free access after an embargo is dependent on the subscription model for its existence.

Under agreements between learned societies and publishers, publishers of learned society journals may pass some of their profits onto the societies to support the society's activities, or to fund society staff or appointees (e.g., editors but not peer reviewers). We wondered whether the quality of these society-based journals would suffer if the publishers' revenues declined.

Usage criteria (both during and postembargoes) would be important measures. Publishers may not know what usage their research articles are getting because the articles (or versions of them) may be distributed across multiple platforms. There was agreement that traffic on websites for journals, especially those that also rely on advertising dollars (such as medical journals), are reduced when the attention is pulled to other sites (e.g., institutional repositories). This potentially affects advertising revenue, which in turn can impact the financial model of those publications and the trickle down funds going to learned societies and journal editors. In addition, dispersed usage makes consolidated usage data difficult, if not impossible, to collect. Since usage data are an important criterion used by libraries and other subscribers, reduced usage numbers may affect renewal decisions. 
Capturing usage would help alleviate this potential problem. We did not have time to consider the relationship between an embargo period, its duration, and the citation advantage of having the article open.

Embargoes on Accepted Manuscripts (AMs) in repositories are contentious, with qualified acceptance that these are a transitional mechanism in a shift to full open access. ${ }^{3}$ The causal link between the length of embargo and cancellation of subscriptions is not proven. ${ }^{4}$ The September 2013, the UK Business, Innovation and Skills Committee's Fifth Report: Open Access stated that "There is no available evidence base to indicate that short or even zero embargoes cause cancellation of subscriptions." ${ }^{5}$ In 2012, the Committee for Economic Development Digital Connections Council, in "The Future of Taxpayer-Funded Research: Who Will Control Access to the Results?," concluded that "No persuasive evidence exists that greater public access as provided by the NIH policy has substantially harmed subscriptionsupported STM publishers over the last four years or threatens the sustainability of their journals." "There is good reason, however, to question the notion that subscribers would continue to pay for access if articles were available immediately for free. It has been observed that different disciplines have different tolerances for different embargo lengths. Most of the earliest publications with embargoes have been in biomedicine, where progress is more rapid than many other disciplines. Applying lessons from those examples could be misleading, thus the need for further study.

We explored the duration of embargoes. Scholars in the humanities have expressed concerns that most embargoes are too short, while the social scientists and scientists feel that the value of research is highest during the initial period their articles are available. We wondered briefly if this could be construed as an issue of academic freedom? Other aspects of disciplinary differences need to be considered further. Embargoes straddle the tension between promotion-and-tenure and the academic freedom to publish where the researcher wants.

As we discussed existing embargoes, we wondered how publishers and funders determine embargo periods. Current embargoes range up to 48 months. In 2006, a six-month embargo was set by the Wellcome Trust, which as a research funder had the freedom to set whatever embargo it wanted. The Lancet chose a sixmonth embargo because that was what the competition was doing and their assessment of their subscription base and other business considerations made such a voluntary and reversible embargo feasible. A 12-month embargo for Arts and Humanities was proposed by the Finch Group in the 2012 "Report of the Working Group on Expanding Access to Published Research Findings." 7 These were not based on usage or competition.

What are the consequences when an embargo is breached-the story leaks, the article gets pulled/scooped, patent risk, the publisher may take an economic hit?

Much of the discourse and arguments about embargoes are not evidence based. There is little evidence to support the tenet that sits behind embargoes, which is that if publishers allow researchers to make copies of their work available open access then publishers will lose subscriptions and revenue. If there are sustainabil- 
ity issues for journals, then we need longer-term management in place to work towards full open access.

The conclusion from our discussions was that there needs to be some concrete, rigorous research into the rationale behind embargoes in order to inform publishers, researchers, funders-all of the scholarly communication stakeholders. In response to this, the Embargo workgroup decided that the most effective solution was to collaborate on a research process that would have the buy-in of all stakeholder groups. The overarching question that we want to answer is 'What are the impacts of embargoes on scholarly communication?' with the goal of creating an evidence base for informed discussion about embargoes. The parameters of the study must be articulated so that it would be unbiased and cover geographical, cultural, disciplinary, etc., differences.

We decided that if the research found there was a case for publication embargoes, then there should be agreement on the metrics used to determine the length of an embargo. We hope that one outcome of this research would be standards for embargoes.

\section{Embargo Research Overview: Creating the evidence base for embargoes}

The project we propose includes: (1) funder identification (already begun) and brief (drafted), (2) literature review (already begun), (3) case studies analysis, (4) employing researcher(s) and surveying stakeholders, (5) analysis of survey data and presentation at OSI 2017 (by the OSI 2016 Embargo Workgroup).
In terms of governance, the OSI Embargo Workgroup will work together as the steering committee to develop the brief, organize funding and choose the research team to do the work. We will need to engage an independent researcher or research group to ensure impartiality.

1. The biggest issue for the project is funding. We heard from one willing funder during our initial presentation, but we are of the opinion that multiple funders would give the findings a more impartial tone. One member of our group has subsequently identified another possible funding source. The Research Committee of the ACRL or its Research and Scholarly Environment Committee may be able to help. We prepared a preliminary assessment of the time required to do the work (circa 64 working days) and have a rough estimate for the fundraising goal— $\$ 50,000$.

2. The literature review for this project is being organized on Mendeley: https://www.mendeley.com/groups/ 8651051/_/papers/

3. Two existing case studies may provide relevant evidence if the commercial publishers are willing to share what they have learned. In both cases, there has been a move from an embargo period for green $\mathrm{OA}$ to removing embargoes completely. There should be enough data to indicate if these decisions have resulted in subscription cancellations or funding alternatives.

- Taylor and Francis began a trial in 2011 to allow immediate green OA for their library and information science journals. ${ }^{8}$ As part of the pilot, T\&F/Routledge conducted a survey, canvassing 
opinions on its Library and Information Science Author Rights initiative. T\&F/Routledge also investigated author and researcher behavior and views on author rights policies, embargoes, and posting work to repositories. The survey elicited over 500 responses.

- In 2013 Sage moved to an immediate green policy. ${ }^{10}$

4. Employing researcher(s) to develop and conduct the survey of stakeholders: to be determined based on availability of funding. Who are the stakeholder groups, however, and how do we reach them? Stakeholders include authors, authors' institutions, repository managers, journals, publishers (including library publishers and university presses), learned societies, research community (disciplinary norms), users/public, research funders (e.g., RCUK, NSF, NIH) universities, and libraries.

5. The OSI Embargo Workgroup will analyze the survey data and present it to OSI 2017, in addition to publishing it in (immediate) open access journals.

As the OSI program predicted, we worked together "to more effectively advance our common interest in improving access to knowledge for the betterment of society." Looking at the member and publisher supported journals, we wondered how long it would be before the business model changes to full open access? Unfortunately, the discussion to date has largely been ideologically driven and shared through anecdotes, but there have not been any studies done or empirical data gathered. Therefore, we unanimously decided our contribution to the issues surrounding embargoes within the scholarly communication arena would be to see that data are gathered, perhaps beginning the Wikipedia of Embargoes.

In Appendix A (below), we list some of the questions the survey should cover in order to gather the data that will address the research question, What are the impacts of embargoes on scholarly communication?' 


\section{OSI Embargo Workgroup}

Group delegates represent a wide mix of interest groups and representatives from Australia, the United Kingdom, and the United States:

Glenorchy Campbell, Managing Director, British Medical Journal North America

Gregg Gordon, President, Social Science Research Network

Laura Helmuth, Incoming President, National Association of Science Writers

Danny Kingsley, Head of Scholarly Communication, Cambridge University (previously from Australia)

Eric Massant, Senior Director of Government and Industry Affairs, RELX Group

Audrey McCulloch, Chief Executive, Association of Learned and Professional Societies

Gail McMillan, Director of Scholarly Communication, Virginia Tech

Tony Peatfield, Director of Corporate Affairs, Medical Research Council, Research Councils UK

Ann Riley, President, Association of College and Research Libraries

Will Schweitzer, Director of Product Development, AAAS/Science

Keith Webster, Dean of Libraries, Carnegie Mellon University (has worked in Australia) 


\section{Appendix A}

\section{Survey to determine: What are the impacts of embargoes on scholarly communication?}

Throughout our two days of discussion, the OSI Embargo Workgroup formulated questions (below, in no particular order) for the survey of stakeholders to address the research question: "What are the impacts of embargoes on scholarly communication?"

- Who needs access?

- How are embargoes determined?

- How do researchers/students find research articles?

- Are embargoes different depending on the academic discipline?

- What will be the anticipated effect of embargoes in five years' time?

- Are publishers' policies different based on frequency of publication or usage levels of articles?

- What other criteria do publishers use to determine embargoes?

- What is the impact of embargoes on various stakeholder groups: publishers, libraries, and researchers (by discipline)?

- What are the trends?

- What are the publishers' policies now, what might they be next year, in three years?

- How much do embargoes affect access to research? By whom?

- How do faculty find embargoed articles vs. how do students find them?

- What is the data from request access/copy buttons in repositories and libraries during embargoes and post-embargoes?

- What is the number of 'turn-aways' from publishers' platforms for embargoed articles?

- What is the level of usage from 'Get it Now' (i.e., the library obtains a copy through interlibrary loan or document delivery and absorbs the cost)?

- What is the cost for document delivery library services for embargoed articles and others?

- How many attempts to access articles are being turned away on publishers' platforms?

- How many purchases from publishers' sites: pay per views?

- What are the data for libraries paying access fees for their community members for document delivery including inter-library loans for embargoed articles?

- Do libraries have data on their users encountering embargoes during database searching? (If so, annual reports of this data might suggest trends.)

- Is there a way to capture more OA usage by article/journal?

- What impact characteristics should be considered regarding journals, e.g., JIF?

- What has been the impact on infrastructure for journals that have gone fully OA?

- What would be the anticipated impact should OA with embargoes become universal? 
- Are the access models based on embargoes interim or long-term solutions?

- How much open access (quantity and user groups) is there through free (or low cost) access programs?

We'll need to define terms carefully, e.g., access; SME: small/medium enterprises; Freemium: final version is free to read but there are no links to references or other "services" (e.g., can't print).

\section{Notes:}

1 This report draws heavily on Danny Kingsley's meeting notes and blog, "Watch this space - the first OSI workshop," April 24, 2016, as of May 19, 2016 :

https:/ / unlockingresearch.blog.lib.cam.ac.uk/?p=614

2 "Global scientific community commits to sharing data on Zika," (Press Release), Wellcome Trust, 10 February, 2016, as of May 19, 2016: http:/ /www.wellcome.ac.uk/News/Mediaoffice/Press-releases/2016/WTP060169.htm 3 "Statement about embargo periods," Confederation of Open Access Repositories, as of May 19, 2016: https://www.coar-repositories.org/activities/advocacy-leadership/aligningrepository-networks-across-regions/statement-about-embargo-periods/

4 "Half-life is half the story" (blog post), University of Cambridge Office of Scholarly Communication, as of May 19, 2016: https://unlockingresearch.blog.lib.cam.ac.uk/?p=331

5 “Open Access, Fifth Report of Session 2013-14,” House of Commons Business, Innovation and Skills Committee, September 2013, as of May 19, 2016: http://www.publications.parliament.uk/pa/cm201314/cmselect/cmbis/99/99.pdf 6 "The Future of Taxpayer-Funded Research: Who Will Control Access to the Results?", Committee for Economic Development, February 09, 2012, as of May 19, 2016: https://www.ced.org/reports/single/the-future-of-taxpayer-funded-research-who-willcontrol-access-to-the-resul

7 "Report of the Working Group on Expanding Access to Published Research Findings," The Finch Group, 19 March 2013, as of May 19, 2016:

http://www.researchinfonet.org/publish/finch/

8 Routledge trials new author rights policy for Library and Information Science Journals (Press release), November 1, 2011, as of May 19, 2016: http:/ / www.tandf.co.uk/journals/press/LIS-author-rights-pr.pdf 9 Author Rights Pilot (undated web page), Author Services, Taylor \& Francis, as of May 19, 2016: http://authorservices.taylorandfrancis.com/author-rights-pilot/

10 The Green Route - Open Access Archiving Policy (undated web page), Sage Publications, as of May 19, 2016: https://uk.sagepub.com/en-gb/eur/the-green-route- $\% \mathrm{E} 2 \% 80 \% 93$ open-access-archiving-policy 